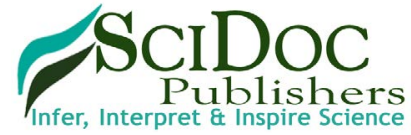

\section{Perioperative Anaesthesia Management During Minimally Invasive Surgery in Patients with Aortic Valve Diseases}

\author{
Research Article
}

Lafci ${ }^{1 *}$, Gokcinar $\mathrm{D}^{1}$, Gunertem E $\mathrm{E}^{2}$, Gunaydin $\mathrm{S}^{2}$, Gogus $\mathrm{N}^{1}$

${ }^{1}$ Department of Anesthesiology, Ankara Numune Training and Research Hospital, Ankara, Turkey.

${ }^{2}$ Department of Cardiovascular Surgery, Ankara Numune Training and Research Hospital, Ankara, Turkey.

\title{
Abstract
}

Objective: Minimally invasive aortic valve replacement is a common procedures in practice. Our aim is to present our experiences on our anaesthesia applications during these operations.

Methods: Upon the approval of the Hospital Ethics Committee, data of the patients that underwent minimal invasive aortic valve surgery between 1 January 2017 and 31 August 2017 were analysed retrospectively. Recorded details were age, gender, Body Mass Index (BMI), American Society of Anesthesiologists (ASA) classification, New York Heart Association classification (NYHA), Ejection Fraction (EF), Euroscore II, smoking history, accompanying diseases, cardiopulmonary bypass duration, aortic cross-clamping time, presence or absence of ventricular fibrillation, number of blood products given, time spent in intensive care unit, hospital stay, and intensive care mortality.

Results: Results from a total of 22 patients were analysed. Median value for age was 55, minimum was 36, and maximum was 83. Of the patients, $59 \%$ was female, while $41 \%$ was male. It was found that $68 \%$ of the patients were classified as NYHA II and $32 \%$ fell into NYHA III. Euroscore II percentage was established as median 1.73 (minimum 0.79-maximum 2.75). Median cardiopulmonary bypass time was 120 minutes (minimum 73 minutes-maximum 165 minutes), and median cross-clamp time was 95 minutes (minimum 47 minutes-maximum 127 minutes). Median length of stay in intensive care unit was 15 hours (minimum 8 hours-maximum 23 hours), median hospitalization duration was established as 5 days (minimum 3 days-maximum 9 days).

Conclusion: Anaesthesia applications in minimally invasive surgery carried out for aortic valve diseases predominantly include preoperative preparation, perioperative monitoring, and postoperative pain management.

Keywords: Aortic Stenosis; Aortic Valve Replacement; Minimally Invasive Surgery; Anaesthesia.

\section{Introduction}

Aortic valve diseases can cause dyspnoea, palpitations, syncope and anginal symptoms, and it can also lead significant low cardiac output and sudden death. In aortic stenosis, progressive left ventricular outflow tract obstruction increases left ventricular systolic pressure. While increased left ventricular systolic pressure raises myocardial oxygen requirement, it also decreases oxygen delivery and causes subendocardial ischemia. In such patients, compensatory left ventricular hypertrophy develops, and this causes diastolic dysfunction and pulmonary congestion. Aortic valve diseases may require conventional or minimal invasive surgical methods along with repair or replacement in addition to medical treatment. While conventional median sternotomy provides a good surgical exposure, serious complications such as mediastinitis can effect directly to the survey. Compared to classic median sternotomy, aortic valve replacement via right anterior mini-thoracotomy bears such advantages as the preservation of anatomical integrity, less bleeding and lower transfusion requirement, decreased stress response to surgery, lower respiratory complications, lowered complications of wound healing, provision of faster recovery, and related shortened hospital stays [2-9]. Minimal invasive heart surgery requires a unique anaesthesia method. It is important to establish functional deterioration due to aortic valve disease and accompanying comorbid conditions, and if possible, to apply treatments that would provide their relief during preoperative preparations. During anaesthesia induction and maintenance, monitoring and application of anaesthetic agents and other drugs

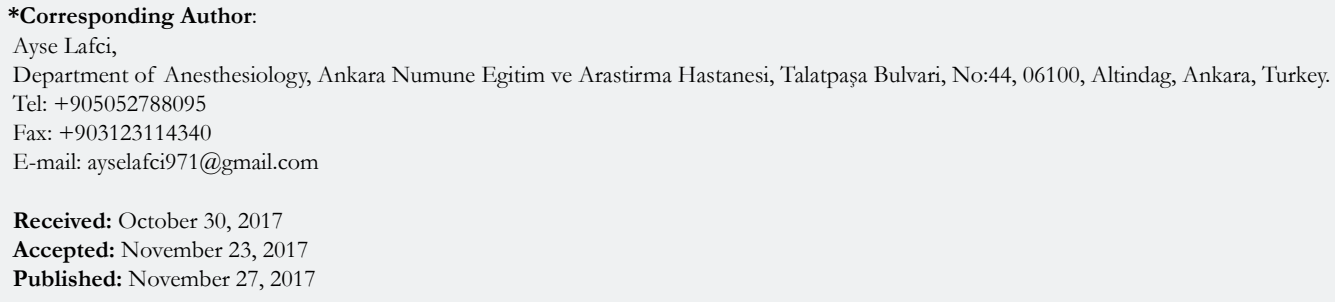

Citation: Lafci A, Gokcinar D, Gunertem E, Gunaydin S, Gogus N. Perioperative Anaesthesia Management During Minimally Invasive Surgery in Patients with Aortic Valve Diseases. Int J Anesth Res. 2017;5(9):485-489. doi: http://dx.doi.org/10.19070/2332-2780-1700098

Copyright: Lafci $\mathbf{A}^{\circ}$ 2017. This is an open-access article distributed under the terms of the Creative Commons Attribution License, which permits unrestricted use, distribution and reproduction in any medium, provided the original author and source are credited. 
and replacement therapies in order to preserve the haemodynamic stability require patient-specific attention. Single-lung ventilation can be implemented in order to increase surgical view. Shuntincreasing effects of anaesthetic agents can be observed during one-lung ventilation. Desflurane blood-gas partition is a low coefficient inhalation anaesthetic. It was shown to provide both early recovery and early discharge [10-12].

It is important to proctect myocardium which has been hypertrophied and dilated during cardiopulmonary bypass. For this reason, a suitable cardioplegia method should be selected. Del Nido cardioplegia solution is a cheap method that does not contain glucose and calcium and that is mostly used as a single dose [13]. Postoperative pain characteristics are different in median sternotomy and anterior mini-thoracotomy, and various treatment approaches may be required [14-16].

In literature there are few studies which is about perioperative anaesthesia management during minimally invasive aortic valve surgery. Anaesthesiologists have a vital role in such a possibly complicated patient group. Our aim is to share our experiences on this issue and to review other studies published in the field.

\section{Methods}

This study was conducted at a tertiary care hospital upon the approval of the Hospital Ethics Committee. Patients who underwent aortic valve replacement via right anterior mini-thoracotomy in the Cardiovascular Surgery Clinic between 1 January 2017 and 31 August 2017 were included in the study. Exclusion criteria were patients below the age of 18 , patients who underwent median sternotomy, and patients without available records. Data of the patients included in the study were analysed retrospectively from the hospital's electronic medical records system. Age, gender, BMI, ASA and NYHA classifications, EF, Euroscore II, smoking history, accompanying diseases, cardiopulmonary bypass time, cross-clamp time, presence of ventricular fibrillation, number of blood products received, intensive care unit length of stay, hospital stay, and intensive care unit mortality were recorded.

As premedication, all patients were given $5 \mathrm{mg}$ diazepam 8 hours before the operation orally. Thirty minutes before the surgery, $0.1 \mathrm{mg} / \mathrm{kg}$ morphine was administered intramuscularly. Patient taken to the operation room underwent, six-channel ECG, pulse oximetre, invasive arterial blood pressure, central venous pressure measurement through jugular central vein catheterisation, bispectral index, and Near-Infrared Spectroscopy (NIRS). External defibrillator pads were appropriately placed on the back of patients. Following the anaesthesia induction with $0.04 \mathrm{mg} / \mathrm{kg}$ midazolam, $10 \mathrm{mcg} / \mathrm{kg}$ fentanyl, $1 \mathrm{mg} / \mathrm{kg}$ propofol, and $0.5 \mathrm{mg} / \mathrm{kg}$ rocuronium, endobronchial intubation was conducted with left double-lumen tube. Correct placement of double-lumen tube was provided with auscultation. Controlled ventilation was ensured in manner suitable for each patient so as to provide end-tidal carbon dioxide within normal limits. Anaesthesia was maintained with $2-6 \%$ desflurane, $50 \%$ oxygen and $50 \%$ air mix. Rocuronium and fentanyl were administered every 45 minutes as intravenous bolus. Through right internal jugular vein, central venous catheter and oral transoesophageal echocardiography (TEE) probe were placed. Patient was given 30 degree left lateral decubitus position. Following suitable surgical area cleaning and surgical covering, low-dose heparinisation was carried out. Femoral artery and vein were cannulised. Using double-lumen tube, right lung ventilation was stopped and only the left lung ventilation was permitted. Right lung was deflated and right anterior mini-thoracotomy incision of $4-5 \mathrm{~cm}$ was conducted. Heparinisation of $300 \mathrm{IU} \cdot \mathrm{kg}^{-1}$ dosage was carried out with activity clotting time being lower than 400 seconds. Cardiopulmonary bypass was conducted by using roller pump and with $2.4 \mathrm{~L} . \mathrm{m}^{2} \cdot \mathrm{min}^{-1}$ non-pulsatile current. During cardiopulmonary bypass, systemic hypothermia was maintained at $30-32^{\circ} \mathrm{C}$. After aortic cross-clamp was placed, cardia arrest was conducted Del Nido cardioplegia solution was administered via antegrade approach for the myocardial protection. Following the replacement of prosthetic valve, deairing was done with the help of TEE. Patient temperatures were increased to $37^{\circ} \mathrm{C}$ after the removal of cross-clamp. Patients who developed ventricular fibrillation were defibrillated with the help of external pads. After establishing haemodynamic stability, patients were separated from cardiopulmonary bypass. Protamine was administered after decanulation. When surgical procedure was completed, doublelumen tube and TEE probe were removed. Patient was then intubated with single-lumen endotracheal tube. In order to contribute to postoperative analgesia, $20 \mathrm{ml} 0.25 \%$ bupivacaine was injected in the wound site and its periphery in thoracotomy site. Following surgery, patients were transferred to cardiopulmonary surgery intensive care unit in a motorised matter. During the post-operative period, multimodal analgesia was ensured with paracetamol, tramadol, and diclofenac.

\section{Statistical Analysis}

All analyses were carried out by using SPSS (version 21.0) software. Categorical variables in patients were expressed by numbers and percentage. Whether the distribution of numerical data was normal or not was evaluated by histogram analysis. Results that did not manifest normal distribution were expressed by median value, minimum and maximum.

\section{Results}

Aortic valve replacement via right anterior mini-thoracotomy was conducted on a total of 22 patients within eight months between 1 January 2017 and 31 August 2017. Table 1 shows demographic and clinical data of these patients. Median value of age was 55 with minimum being 36 and maximum 83 . Of the patients, $59 \%$ were female and $41 \%$ were male. Functional status of $68 \%$ of patients were NYHA II and in $32 \%$ of them were in NYHA III. Euroscore II percentage was found as median 1.73 (minimum 0.79 -maximum 2.75). Of the patients, $41 \%$ had smoking history. Among the accompanying diseases, the most common ones were established as hypertension (41\%) and diabetes mellitus (41\%).

Median cardiopulmonary bypass time was 120 minutes (minimum 73 minutes-maximum 165 minutes) and median cross-clamp time was 95 minutes (minimum 47 minutes-maximum 127 minutes). Ventricular fibrillation occurred in $27 \%$ of these patients,. While median length of stay in intensive care unit was established as 15 hours (minimum 8 hours-maximum 23 hours), median hospitalization duration was 5 days (minimum 3 days-maximum 9 days) (Table 2). All patients were administered a total of 18 units of erythrocyte suspension and 20 units of fresh frozen plasma. Intensive care unit mortality rate of patients included in the study was $9 \%$. 


\section{Discussion}

We found the intensive care unit mortality rate in patients that underwent aortic valve replacement via right anterior minithoracotomy as $2 \%$. Minimal invasive techniques have become widespread in recent years in the field of surgery. Aortic valve replacement via right anterior mini-thoracotomy conducted in our country in a few centres fall into the category of minimal invasive procedures. Since minimal invasive heart surgery techniques are different from conventional techniques, there are certain issues that anaesthesiologists need to consider. In addition to clinical conditions of aortic valve patients being critical, anaesthesia and surgical operation bear additional risks.

Anaesthesiologists need to evaluate complaints, symptoms, and physical examination findings due to both aortic valve pathology and accompanying diseases of the patient by conducting preoperative patient visits. Single-lung ventilation provides a better surgical view in aortic valve replacement surgeries by right anterior mini-thoracotomy compared to double-lung ventilation. In an observational study conducted on 187 patients, Stolinski et al., compared the effects of single-lung and double-lung ventilations on respiratory functions during aortic valve replacement surgery by right anterior mini-thoracotomy. They observed that singlelung ventilation and double-lung ventilation did not pose significant differences in terms of respiratory functions [17]. A decision should be made for patients that are to undergo heart surgery by mini-thoracotomy on whether they would tolerate single-lung ventilation by analysing pulmonary function tests, arterial blood gas, and postero-anterior pulmonary roentgenography in the preoperative period $[1,14]$. A prolonged single-lung ventilation may not be maintained in patients with such pathologies as active bronchospasm or bullous lungs. Single-lung ventilation may cause an increase in the pulmonary artery pressure, decreased cardiac output, hypoxia and hypercarbia [18]. It is of utmost importance to bring the respiratory functions to the optimal level before operating on these patients. Of our patients that had severe chronic pulmonary disease received medical treatment in the preoperative period to recover respiratory functions by consulting chest disease specialists. Smoking should be quit as soon as possible. It bears importance to stop smoking at least two weeks before the surgery in order to decrease perioperative complications [14].

A low-dose oral benzodiazepine is recommended a night before the surgery as premedication in patients being prepared for minimal invasive open-heart surgery [14]. In addition, administration of intramuscular morphine half an hour before the operation would lead to patient being calmer and vital findings being stable [19].

In preoperative cardiovascular evaluation of patients with aortic valve disease, functional condition of the heart should be established through obtaining the history, physical examination, and invasive and non-invasive techniques. Among the non-invasive techniques are Holter ECG and echocardiography. Cardiac catheterisation is among invasive techniques. Severe aortic stenosis is known by mean pressure gradient being higher than $40 \mathrm{mmHg}$, and aortic valve site being under $1 \mathrm{~cm}^{2}$ or being symptomatic [20].

Perioperative monitoring bears utmost importance in terms of establishing cardiac complications in aortic valve operations. Use of TEE is quite beneficial in aortic valve surgery that utilises in-

Table 1. Demographic and clinical data of patients.

\begin{tabular}{|c|c|}
\hline Age (Years) & $55(36-83)$ \\
\hline Sex (M/F) & $9(41 \%) / 13(59 \%)$ \\
\hline BMI & $27.5(16.2-33.4)$ \\
\hline ASA II/III & $15(68 \%) / 7(32 \%)$ \\
\hline NYHA II/III & $15(68 \%) / 7(32 \%)$ \\
\hline Ejection fraction ( $\%)$, EF $=30-50 \% / \mathrm{EF}>50 \%$ & $10(45 \%) / 12(55 \%)$ \\
\hline Euroscore II $(\%)$ & $1.73(0.79-2.75)$ \\
\hline Smoking history & $9(41 \%)$ \\
\hline Accompanying diseases & Number $(\%)$ \\
\hline Hypertension & $9(41 \%)$ \\
\hline Diabetes mellitus & $9(41 \%)$ \\
\hline Atrial fibrillation & $2(9 \%)$ \\
\hline Chronic Obstructive Pulmonary Disease & $4(18 \%)$ \\
\hline Chronic renal disease & $1(5 \%)$ \\
\hline
\end{tabular}

Values are given as median (minimum-maximum) and in numbers $(\%)$

Table 2. Perioperative data of patients that underwent aortic valve replacement surgery by right anterior mini-thoracotomy.

\begin{tabular}{|c|c|}
\hline Cardiopulmonary bypass time (minutes) & $120(73-165)$ \\
\hline Cross-clamp time (minutes) & $95(47-127)$ \\
\hline Ventricular fibrillation & $6(27 \%)$ \\
\hline ICU length of stay (hours) & $15(8-23)$ \\
\hline Hospital stay (days) & $5(3-9)$ \\
\hline Transfused erythrocyte suspension (n) & 18 \\
\hline Transfused fresh frozen plasma (n) & 20 \\
\hline Intensive care unit mortality (n) & $2(9 \%)$ \\
\hline
\end{tabular}

Values are given as median (minimum-maximum) and in numbers $(\%)$. 
vasive techniques. Owing to TEE, removal of air also known as deairing is ensured in addition to the evaluation of myocardial ischemia, heart wall abnormalities, left ventricular diastolic functions, condition of volume, and catecholamine treatment [21-23]. Compared to other haemodynamic monitoring methods, the advantages of TEE include its ability to place and apply in a short time. However, it has such disadvantages as inability to provide constant monitoring, expensiveness, dependent on operator training, and the risk of gastrointestinal perforation [24, 25].

Pulmonary artery catheter may be utilised for cardiac surgery in patients with high risk that requires establishing cardiac output syndrome, pulmonary hypertension, and right and left ventricular dysfunction. However, it is not recommended for patients with low perioperative risk [26-30]. Such minimally invasive cardiac output measurement methods such as transpulmonary thermodilution and pulse contour analysis are alternatives to pulmonary artery catheterisation [31-33]. In minimally invasive cardiac surgery, further studies are needed to establish the results in patients that receive such haemodynamic measurement methods that are less invasive.

Following anaesthesia induction, anaesthesia can be maintained with volatile inhalation agents. Volatile inhalation agents were found to decrease postoperative troponin I levels in patients that undergo cardiac surgery [34-36]. Of the inhalation agents, desflurane was shown to provide a decrease in markers of myocardial necrosis and recovery of postoperative myocardial functions [37].

Durign aortic valve surgery, myocardial damage that may occur during aortic cross-clamp can be prevented by cardioplegia methods. Del Nido cardioplegia solution was suggested to increase tolerance against intracellular calcium increase that causes irreversible myocyte damage and to provide sufficient protection with a single dose through uniform distribution in myocardium [38-43]. When compared to other conventional cardioplegia methods in some studies, aortic cross-clamp time was found as shorter in patients that receive Del Nido cardioplegia $[44,45]$. In contrast, in a study by Vistarini et al., Del Nido cardioplegia was shown not to shorten aortic cross-clamp time [46]. In our study, all patients were administered Del Nido cardioplegia. Both ease of application and uninterrupted surgery along with lower costs were ensured this way by administering only a single dose of cardioplegia. Minimally invasive surgery bears such advantages as less blood transfusion, better pulmonary functions, shorter hospital stays, and smaller skin scars from a cosmetic point of view compared to conventional heart surgery [47-55].

Postoperative pain management is quite important following heart surgery since pain causes tachycardia and hyperventilation. Occurrence of hypoxia during the period of heightened myocardial oxygen demand exacerbates the clinical picture of patient [14]. Multimodal analgesia is a recommended method in recent years for postoperative pain management. A well pain management ensures early mobilisation and fast recovery [56].

\section{Conclusion}

In minimally invasive surgery conducted for aortic valve diseases, anaesthesiologists should carefully complete preoperative preparation. Technical equipment suitable for perioperative monitoring should be used and anaesthesia applications should be specific to this operation should be carried out.

\section{References}

[1]. Chacko M, Weinberg L. Aortic valve stenosis: Perioperative anaesthetic implications of surgical replacement and minimally invasive interventions. Continuing Education in Anaesthesia, Critical Care and Pain. 2012 Jul 5;12(6):295 - 301

[2]. Cosgrove DM, Sabik JF. Minimally invasive approach for aortic valve operations. Ann Thorac Surg. 1996 Aug;62(2):596 - 7. PubMed PMID: 8694642.

[3]. Detter C, Deuse T, Boehm DH, Reichenspurner H, Reichart B. Midterm results and quality of life after minimally invasive vs. conventional aortic valve replacement. Thorac Cardiovasc Surg. 2002 Dec;50(6):337-41. PubMed PMID: 12457309

[4]. Schmitto JD, Mokashi SA, Cohn LH. Minimally-invasive valve surgery. J Am Coll Cardiol. 2010 Aug 3;56(6):455-62. PubMed PMID: 20670754.

[5]. Glauber M, Miceli A, Bevilacqua S, Farneti PA. Minimally invasive aortic valve replacement via right anterior minithoracotomy: early outcomes and midterm follow-up. J Thorac Cardiovasc Surg. 2011 Dec;142(6):1577-79. PubMed PMID: 21724194.

[6]. Lamelas J, Sarria A, Santana O, Pineda AM, Lamas GA. Outcomes of minimally invasive valve surgery versus median sternotomy in patients age 75 years or greater. Ann Thorac Surg. 2011 Jan;91(1):79-84. Pubmed PMID: 21172490.

[7]. Phan K, Xie A, Tsai YC, Black D, Di Eusanio M, Tristan D, et al. Ministernotomy or minithoracotomy for minimally invasive aortic valve replacement: a Bayesian network meta-analysis. Ann Cardiothorac Surg. 2015 Jan;4(1):3-14. PubMed Central PMCID: PMC4311162.

[8]. Terwelp MD, Thourani VH, Zhao Y, Balan P, Loghin C, Estrera A, et al. Minimally Invasive Versus Transcatheter and Surgical Aortic Valve Replacement: A Propensity Matched Study. J Heart Valve Dis. 2017 Mar;26(2):14654. PubMed PMID: 28820543.

[9]. Nishimura RA, Otto CM, Bonow RO, Carabello BA, Erwin JP, Fleisher LA, et al. 2017 AHA/ACC Focused Update of the 2014 AHA/ACC Guideline for the Management of Patients With Valvular Heart Disease: A Report of the American College of Cardiology/American Heart Association Task Force on Clinical Practice Guidelines. Circulation. 2017 Jun 20;135(25):1159-95. PubMed PMID:28298458.

[10]. Apfelbaum JL, Walawander CA, Grasela TH, Wise P, McLeskey C, Roizen $\mathrm{MF}$, et al. Eliminating intensive postoperative care in same-day surgery patients using short-acting anesthetics. Anesthesiology. 2002 Jul;97(1):66-74. PubMed PMID: 12131105.

[11]. Song D, Joshi GP, White PF. Fast-track eligibility after ambulatory anesthesia: a comparison of desflurane, sevoflurane, and propofol. Anesth Analg. 1998 Feb;86(2):267-73. PubMed PMID: 9459231.

[12]. Gökçek E, Kaydu A, Akdemir MS, Akil F, Akıncı IO. Early postoperative recovery after intracranial surgical procedures. Comparison of the effects of sevoflurane and desflurane. Acta Cir Bras. 2016 Sep;31(9):638-44.

[13]. Matte GS, del Nido PJ. History and Use of del Nido Cardioplegia Solution at Boston Children's Hospital. J Extra Corpor Technol. 2012 Sep;44(3):98103. PubMed PMID: 23198389.

[14]. Ganapathy S. Anaesthesia for minimally invasive cardiac surgery. Best Pract Res Clin Anaesthesiol. 2002 Mar;16(1):63-80. PubMed PMID: 12491544.

[15]. Abe K, Shimizu T, Takashina M, Shiozaki H, Yoshiya I. The effects of propofol, isoflurane, and sevoflurane on oxygenation and shunt fraction during one-lung ventilation. Anesth Analg. 1998 Nov;87(5):1164-9. PubMed PMID: 9806702.

[16]. Diegeler A, Walther T, Metz S, Falk V, Krakor R, Mohr FW. Comparison of MIDCAP versus conventional CABG surgery regarding pain and quality of life. Heart Surg Forum. 1999;2(4):290-5. PubMed PMID: 11276489.

[17]. Stoliński J, Plicner D, Fijorek K, Grudzień G, Kruszec P et al. Respiratory System Function in Patients after Aortic Valve Replacement through Right Anterior Minithoracotomy. Thorac Cardiovasc Surg. 2017 Apr;65(3):18290. PubMed PMID: 26906972.

[18]. Boldt J, Papsdorf M, Uphus D, Müller M, Hempelmann G. Changes in regulators of the circulation in patients undergoing lung surgery. $\mathrm{Br} \mathrm{J}$ Anaesth. 1997 Dec;79(6):733-9. PubMed PMID: 9496204.

[19]. Lyons SM, Clarke RS, Vulgaraki K. The premedication of cardiac surgical patients. A clinical comparison of four regimes. Anaesthesia. 1975 Jul;30(4):459-70. PubMed PMID: 1147187.

[20]. Fleisher LA, Beckman JA, Brown KA, Calkins H, Chaikof EL, Freeman WK, et al. ACC/AHA 2007 guidelines on perioperative cardiovascular evaluation and care for noncardiac surgery: A report of the American College of Cardiology/American Heart Association Task Force on Practice Guidelines (Writing Committee to Revise the 2002 Guidelines on Perioperative Car- 
diovascular Evaluation for Noncardiac Surgery): Developed in collaboration with the American Society of Echocardiography, American Society of Nuclear Cardiology, Heart Rhythm Society, Society of Cardiovascular Anesthesiologists, Society for Cardiovascular Angiography and Interventions, Society for Vascular Medicine and Biology, and Society for Vascular Surgery. J Am Coll Cardiol. 2007 Oct 23;50(7):e159-241. PubMed PMID: 17950140

[21]. Click RL, Abel MD, Schaff HV. Intraoperative transesophageal echocardiography: 5-year prospective review of impact on surgical management. Mayo Clin Proc. 2000 Mar;75(3):241-7. PubMed PMID: 10725949.

[22]. Couture P, Denault AY, McKenty S, Boudreault D, Plante F, Perron R, et al. Impact of routine use of intraoperative transesophageal echocardiography during cardiac surgery. Can J Anaesth. 2000 Jan;47(1):20-6. Pubmed PMID: 10626713

[23]. Michel-Cherqui M, Ceddaha A, Liu N, Schlumberger S, Szekely B, Brusset A, et al. Assessment of systematic use of intraoperative transesophageal echocardiography during cardiac surgery in adults: a prospective study of 203 patients. J Cardiothorac Vasc Anesth. 2000 Feb;14(1):45-50. PubMed PMID: 10698392

[24]. Lennon MJ, Gibbs NM, Weightman WM, Leber J, Ee HC, Yusoff IF. Transesophageal echocardiography-related gastrointestinal complications in cardiac surgical patients. J Cardiothorac Vasc Anesth. 2005 Apr;19(2):1415. PubMed PMID: 15868517.

[25]. Piercy M, McNicol L, Dinh DT, Story DA, Smith JA. Major complications related to the use of transesophageal echocardiography in cardiac surgery. J Cardiothorac Vasc Anesth. 2009 feb;23(1):62-5. PubMed PMID: 19058977.

[26]. American Society of Anesthesiologists Task Force on Pulmonary Artery Catheterization. Practice guidelines for pulmonary artery catheterization: an updated report by the American Society of Anesthesiologists Task Force on Pulmonary Artery Catheterization. Anesthesiology. 2003 Oct;99(4):9881014. Pubmed PMID: 14508336.

[27]. Mueller HS, Chatterjee K, Davis KB, Fifer MA, Franklin C, Greenberg $\mathrm{MA}$, et al. ACC expert consensus document. Present use of bedside right heart catheterization in patients with cardiac disease. American College of Cardiology. J Am Coll Cardiol. 1998 Sep;32(3):840-64. PubMed PMID: 9741535.

[28]. Pulmonary Artery Catheter Consensus conference: consensus statement. Crit Care Med. 1997 Jun;25(6):910-25. Pubmed PMID: 9201042.

[29]. Harvey S, Harrison DA, Singer M, Ashcroft J, Jones CM. PAC-Man study collaboration. Assessment of the clinical effectiveness of pulmonary artery catheters in management of patients in intensive care (PAC-Man): a randomised controlled trial. Lancet. 2005 Aug 12;366(9484):472-7. PubMed PMID: 16084255.

[30]. Resano FG, Kapetanakis EI, Hill PC, Haile E, Corso PJ. Clinical outcomes of low-risk patients undergoing beating-heart surgery with or without pulmonary artery catheterization. J Cardiothorac Vasc Anesth. 2006 Jun;20(3):300-6. PubMed PMID: 16750726.

[31]. Rodig G, Prasser C, Keyl C, Liebold A, Hobbhahn J. Continuous cardiac output measurement: pulse contour analysis vs thermodilution technique in cardiac surgical patients. Br J Anaesth. 1999 Apr;82(4):525-30. PubMed PMID: 10472216

[32]. Zöllner C, Haller M, Weis M, Mörstedt K, Lamm P, Kilger E, et al. Beat-tobeat measurement of cardiac output by intravascular pulse contour analysis: a prospective criterion standard study in patients after cardiac surgery. J Cardiothorac Vasc Anesth. 2000 Apr;14(2):125-9. PubMed PMID: 10794327.

[33]. Gödje O, Höke K, Goetz AE, Felbinger TW, Reuter DA, Friedl R, et al. Reliability of a new algorithm for continuous cardiac output determination by pulse-contour analysis during hemodynamic instability. Crit Care Med. 2002 Jan;30(1):52-8. PubMed PMID: 11902287.

[34]. Landoni G, Biondi-Zoccai GG, Zangrillo A, Bignami E, D'Avolio S, Marchetti $\mathrm{C}$, et al. Desflurane and sevoflurane in cardiac surgery: a meta-analysis of randomized clinical trials. J Cardiothorac Vasc Anesth. 2007 Aug ;21(4):502-11.

[35]. De Hert SG, Van der Linden PJ, Cromheecke S, Meeus R, Nelis A, Van Reeth V, et al. Cardioprotective properties of sevoflurane in patients undergoing coronary surgery with cardiopulmonary bypass are related to the modalities of its administration. Anesthesiology. 2004 Aug;101(2):299-310. Pubmed PMID: 15277911

[36]. Bignami E, Guarnieri M, Pieri M, Gerli C, Luca MD, De Simone F, et al. Volatile anaesthetics added to cardiopulmonary bypass are associated with reduced cardiac troponin. Perfusion. 2017 Oct;32(7):547-553. 267659117701562. doi: 10.1177/0267659117701562.

[37]. Meco M, Cirri S, Gallazzi C, Magnani G, Cosseta D. Desflurane preconditioning in coronary artery bypass graft surgery: a double-blinded, randomised and placebo-controlled study. Eur J Cardiothorac Surg. 2007 Aug;32(2):319-25. PubMed PMID: 17574858.

[38]. Matte GS, del Nido PJ. History and Use of del Nido Cardioplegia Solution at Boston Children's Hospital. J Extra Corpor Technol. 2012 Sep;4(3):98103. PubMed PMID: 23198389.

[39]. O'Blenes SB, Friesen CH, Ali A, Howlett S. Protecting the aged heart during cardiac surgery: the potential benefits of del Nido cardioplegia. J Thorac Cardiovasc Surg. 2011 Mar;141 (3):762-70. PubMed PMID: 2065301.

[40]. Sorabella RA, Akashi H, Yerebakan H, Najjar M, Mannan A, Smith CR, et al. Myocardial protection using del nido cardioplegia solution in adult reoperative aortic valve surgery. J Card Surg. 2014 Jul;29(4):445-9. PubMed PMID: 24861160

[41]. Kim K, Ball C, Grady P, Mick S. Use of del Nido Cardioplegia for Adult Cardiac Surgery at the Cleveland Clinic: Perfusion Implications. J Extra Corpor Technol. 2014 Dec;46(4):317-23. PubMed Central PMCID: PMC4557478.

[42]. Yerebakan H, Sorabella RA, Najjar M, Castillero E, Mongero L, Beck J, et al. Del Nido Cardioplegia can be safely administered in high-risk coronary artery bypass grafting surgery after acute myocardial infarction: a propensity matched comparison. J Cardiothorac Surg. 2014 Oct 30; 9:141. PubMed PMID: 25359427.

[43]. Kim JS, Jeong JH, Moon SJ, Ahn H, Hwang HY. Sufficient myocardial protection of del Nido cardioplegia regardless of ventricular mass and myocardial ischemic time in adult cardiac surgical patients. J Thorac Dis. 2016 Aug;8(8):2004-10. PubMed PMID: 27621853.

[44]. Mishra P, Jadhav RB, Mohapatra CKR, Khandekar J, Raut C, Ammannaya GK, et al. Comparison of del Nido cardioplegia and St. Thomas II Hospital solution - two types of cardioplegia in adult cardiac surgery. Kardiochir Torakochirurgia Pol. 2016 Dec;13(4):295-9. PubMed Central PMCID: PMC5233756.

[45]. Pourmoghadam KK, Ruzmetov M, O'Brien MC, Piggott KD, Plancher G, Benjamin T, et al. Comparing del Nido and Conventional Cardioplegia in Infants and Neonates in Congenital Heart Surgery. Ann Thorac Surg. 2017 May;103(5):1550-1556. PubMed PMID: 28190549.

[46]. Vistarini N, Laliberté E, Beauchamp P, Bouhout I, Lamarche Y, Cartier M, et al. Del Nido cardioplegia in the setting of minimally invasive aortic valve surgery. Perfusion. 2017 Mar;32(2):112-7. PubMed PMID: 27469246.

[47]. Mohr FW, Onnasch JF, Falk V, Walther T, Diegeler A, Krakor R, et al. The evolution of minimally invasive valve surgery: 2 year experience. Eur J Cardiothorac Surg. 1999 Mar;15(3): 233-38. PubMed PMID: 1033015.

[48]. Grossi EA, Galloway AC, LaPietra A, İbakove GH, Ursomanno P, Culliford AT, et al. Minimally invasive mitral valve surgery: a 6 -year experience with 714 patients. Ann Thorac Surg. 2002 Sep;74:660-663; discussion 663- 4. PubMed PMID: 12238820.

[49]. Doll N, Walther T, Falk V, Mohr FW Binner C, Bucerius J, et al. Secundum ASD closure using a right lateral minithoracotomy: five-year experience in 122 patients. Ann Thorac Surg. 2003 May;75(5):1527- 30; discussion 1530 31. PubMed PMID: 12735574.

[50]. Mihaljevic T, Cohn LH, Unic D, Aranki SF, Couper GS, Byrne JG. One thousand minimally invasive valve operations: early and late results. Ann Surg. 2004 Sep; 240(3):529-34; discussion 534. Pubmed PMID: 15319724.

[51]. Seeburger J, Borger MA, Falk V, Kuntze T, Czesla M, Walther T, et al. Minimal invasive mitral valve repair for mitral regurgitation: results of 1339 consecutive patients. Eur J Cardiothorac Surg. 2008 Oct;34(4):760 -5. PubMed PMID: 18586512

[52]. Svensson LG, Atik FA, Cosgrove DM, Blackstone EH, Rajeswaran J, Jin U, et al. Minimally invasive versus conventional mitral valve surgery: a propensity-matched comparison. J Thorac Cardiovasc Surg. 2010 Apr;139(4):92632. PubMed PMID: 19945121.

[53]. Suri RM, Burkhart HM, Rehfeldt KH, Enriquez-Sarano M, Daly RC, et al. Robotic mitral valve repair for all categories of leaflet prolapse: improving patient appeal and advancing standard of care. Mayo Clin Proc. 2011 Sep;86(9):838-44. PubMed Central PMCID: PMC3258002.

[54]. Johnston DR, Atik FA, Rajeswaran J, Blackstone EH, Nowicki ER, Gilinov AM, et al. Outcomes of less invasive J-incision approach to aortic valve surgery. J Thorac Cardiovasc Surg. 2012 Oct;144(4):852-8. PubMed PMID: 22244556.

[55]. Goldstone AB, Atluri P, Szeto WY, Trubelja A, Howard JL, Acker MA, et al. Minimally invasive approach provides at least equivalent results for surgical correction of mitral regurgitation: a propensity-matched comparison. J Thorac Cardiovasc Surg. 2013 Mar;145(3): 748-56. PubMed PMID: 23414991.

[56]. Malik V, Jha AK, Kapoor PM. Anesthetic challenges in minimally invasive cardiac surgery: Are we moving in a right direction? Ann Card Anaesth. 2016;19(3):489-97. 